\title{
Disseminated Carcinomatosis of Bone Marrow from Submucosal Carcinoma in Adenoma of the Rectum
}

\author{
Keiji Yoshioka, Hiroyuki Shimizu*, Sadayoshi Yokoo and Hiromu Andachi**
}

\begin{abstract}
A 62-year-old man was admitted because of paresis of the legs and a bleeding tendency. He was diagnosed as metastatic bone cancer with disseminated intravascular coagulation (DIC). In spite of treatment, his general condition progressively deteriorated and he died of respiratory failure 13 days later. Autopsy revealed a carcinoma in adenoma in the rectum. Although the depth of cancer invasion was confined to the submucosal layer, disseminated carcinomatosis of the bone marrow and tumor emboli in blood vessels of the lung were present.
\end{abstract}

(Internal Medicine 31: 1056-1059, 1992)

Key words: bone marrow metastasis, disseminated intravascular coagulation (DIC), rectal
cancer

\section{Introduction}

Disseminated carcinomatosis of the bone marrow is often accompanied by disseminated intravascular coagulation (DIC) (1), and the clinical course is rapid. Most cases of disseminated carcinomatosis of the bone marrow derive from the stomach $(1,2)$; but carcinomatosis arising from the colon is rare (3-7). In this paper, we describe a case of disseminated carcinomatosis of the bone marrow with DIC arising from submucosal carcinoma in adenoma of the rectum.

\section{Case Report}

A 62-year-old man was admitted to the hospital on January 11, 1991 because of paresis of the legs, macrohematuria and nasal bleeding. He had a history of pulmonary tuberculosis of 6 years of age. Three months before admission the patient first noticed lumbago, which gradually worsened. One month before entry he could not walk, and he was unable to stand up one week before admission. Furthermore, he noticed macrohematuria, tarry stool and nasal bleeding two days before admission.

Body temperature was $37.8^{\circ} \mathrm{C}$, pulse 74 beats $/ \mathrm{min}$, respiratory rate 18 breaths/min, and blood pressure $122 / 72$ $\mathrm{mmHg}$. On physical examination the patient was gaunt, showing nasal bleeding and petechia in the anterior chest and abdomen. Neither superficial lymph nodes nor struma was palpated. The lungs were clear, and the heart beat sounds were regular with no murmur. The liver and spleen were not palpated. The genital, prostata and rectum were normal.

The urine showed macrohematuria, giving a $2+$ test for protein. Peripheral blood examination showed a red blood cell count of $4,590,000 / \mathrm{mm}^{3}$, hemoglobin of $14.1 \mathrm{~g} / \mathrm{dl}$, hematocrit of $42.7 \%$, and a white blood cell count of $15300 / \mathrm{mm}^{3}$, consisting of $7 \%$ myelocytes, $1 \%$ metamyelocytes, $62 \%$ neutrophils, $2 \%$ basophils, $4 \%$ eosinophils, $3 \%$ monocytes and $21 \%$ lymphocytes, in addition, the platelet count was $71000 / \mathrm{mm}^{3}$. Moreover, red cell fragmentation was observed. The erythrocyte sedimentation rate was $36 \mathrm{~mm} / \mathrm{h}$. The bleeding time was over 15 minutes, and the coagulation time 13 minutes. The prothrombin time was 13.3 seconds $(46 \%)$ and the activated partial thromboplastin time 44.0 seconds $(62 \%)$. Fibrinogen content of plasma was $142 \mathrm{mg} / \mathrm{dl}$, and the fibrin/fibrinogen degenerative product (FDP) was over $40 \mu \mathrm{g} / \mathrm{dl}$, with antithrombin III of $70.2 \%$. The results of blood chemistry were as follows: total bilirubin $0.7 \mathrm{mg} / \mathrm{dl}$, GOT $166 \mathrm{IU} / 1$, GPT $17 \mathrm{IU} / 1, \mathrm{LDH} 3434 \mathrm{IU} / 1$, ALP $1161 \mathrm{IU} / 1$, total protein 7.1 $\mathrm{g} / \mathrm{dl}$, serum albumin $3.6 \mathrm{~g} / \mathrm{dl}$, creatinine $1.1 \mathrm{mg} / \mathrm{dl}$, Na 142 $\mathrm{mEq} / 1$, K $3.6 \mathrm{mEq} / 1, \mathrm{Cl} 102 \mathrm{mEq} / 1$, Ca $5.0 \mathrm{mEq} / 1$, FBS $99 \mathrm{mg} / \mathrm{dl}$. The results of serological tests were as follows: C-reactive protein $14.1 \mathrm{mg} / \mathrm{dl}$, Ig G $1440 \mathrm{mg} / \mathrm{dl}$, Ig A 229 $\mathrm{mg} / \mathrm{dl}, \mathrm{Ig}$ M $129 \mathrm{mg} / \mathrm{dl}$, CEA $67.9 \mathrm{ng} / \mathrm{dl}$, CA $19-914 \mathrm{U} / \mathrm{ml}$, $\alpha$ FP $2 \mathrm{ng} / \mathrm{dl}$, DUPAN II $28 \mathrm{U} / \mathrm{ml}$, calcitonin $73 \mathrm{pg} / \mathrm{ml}$. A chest X-ray film showed calcification in the left upper lobe. The bone X-ray showed a compression fracture in the

From the First Department of Internal Medicine, *Orthopedic Surgery and ${ }^{*}$ Pathology, Matsushita Memorial Hospital, Osaka

Received for publication October 29, 1991; Accepted for publication May 19, 1992

Reprint requests should be addressed to Dr. Keiji Yoshioka, the First Department of Internal Medicine, Matsushita Memorial Hospital, 2-35, Sotojima-cho, Moriguchi, Osaka 570, Japan 


\section{Carcinomatosis and Rectal Cancer}

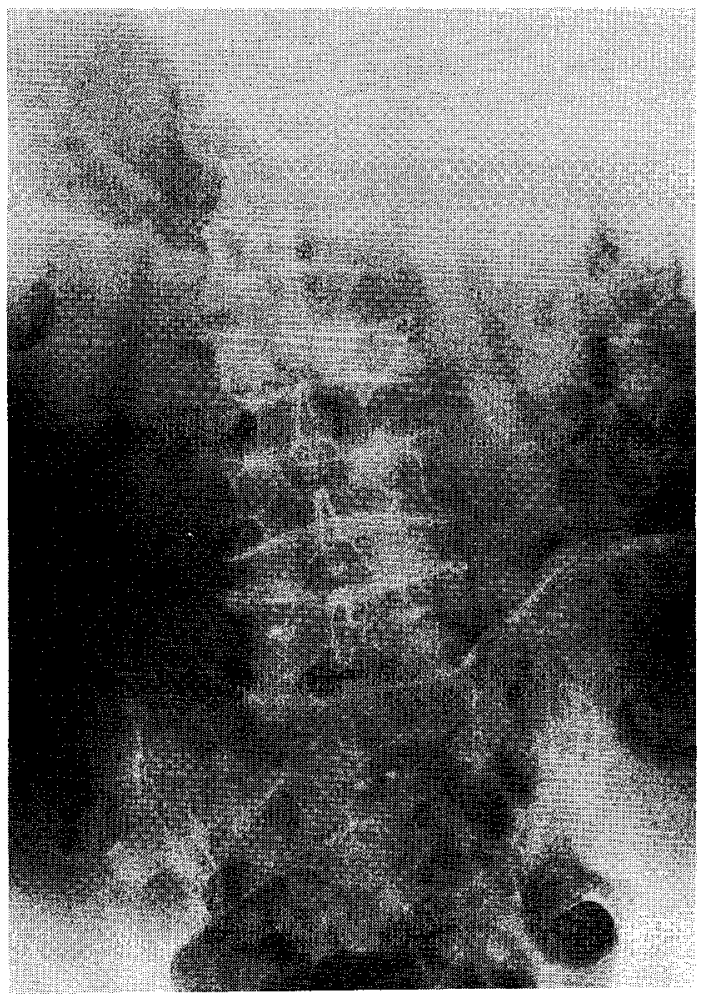

lumbar spine (Fig. 1).

Based on the above findings, we diagnosed his illness as metastatic bone cancer with DIC. There were no tumors in the liver, pancreas, adrenal gland, kidney or bladder, as revealed by computed tomography, ultrasound echography and intravenous pyelography. Gastrofiberscopy showed no tumor, only erosion, in the stomach. Since barium enema and colonoscopic examinations were not performed because of the patient's poor condition, we could not rule out colonic cancer.

To treat DIC, the administration of heparin (10000 $\mathrm{U} /$ day $)$, gebexate mesilate $(20 \mathrm{mg} / \mathrm{kg} /$ day $)$ and antithrombin III was started. However, the bleeding tendency did not improve and microhemangiopathic hemolytic anemia (MHA) developed. His general condition worsened rapidly and dyspnea occurred. He died of respiratory failure on January 22, 1991.

At autopsy, there was a polypoid lesion, measuring $2.5 \times 1.8 \times 2.0 \mathrm{~cm}$, in the rectum $12 \mathrm{~cm}$ distant from the anus. Macroscopically it was the subpedunclated type (Ips)

Fig. 1. Bone X-ray of the spine showing a multiple compression fracture.
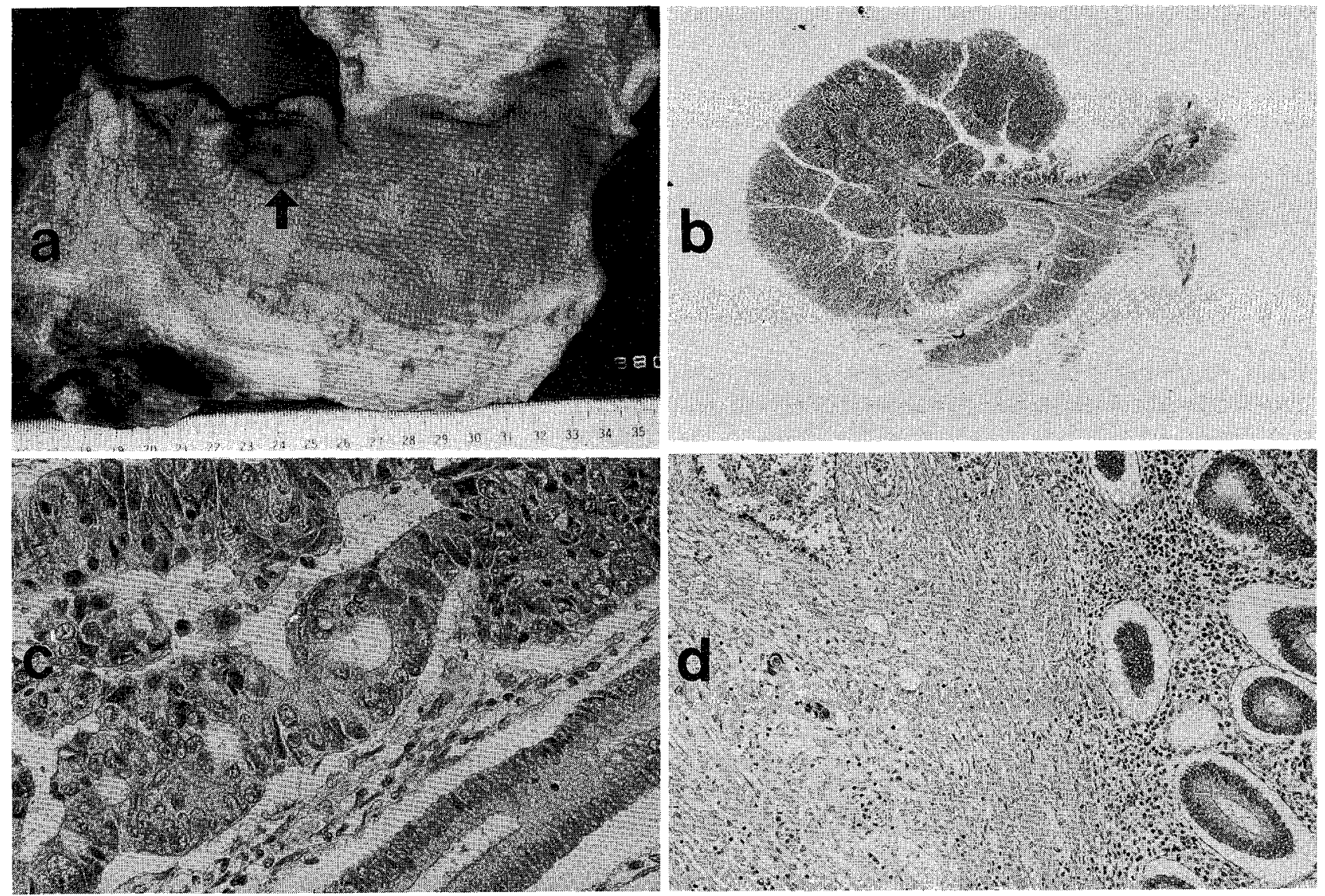

Fig. 2. Resected specimen showing a subpedunclated polypoid lesion (arrow) (a). Cross-section of the tumor showing moderately differentiated adenocarcinoma in adenoma; the depth of invasion reached the submucosal layer (b, hematoxylin-eosin stain, $\times 1)$. Close-up view of the tumor $(c, \times 100)$. Lymphatic and venous $(\mathrm{d}, \times 40)$ permeation are seen in the submucosal layer. 


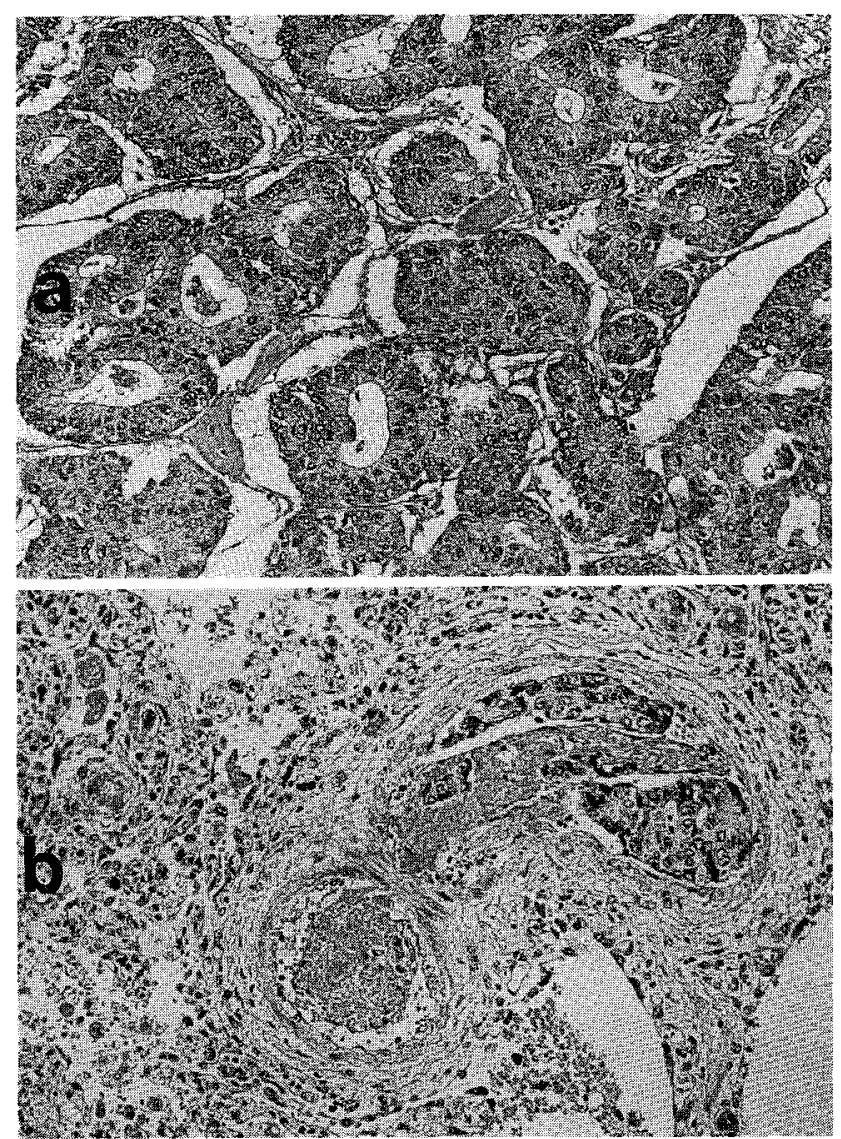

Fig. 3. Microscoipic bone marrow section showing a diffusely infiltrative metastatic carcinoma (a, hematoxylin-eosin stain, $\times 40$ ). Microscopic lung section showing tumor emboli in blood vessels (b, HE stain, $\times 40$ ).

early colonic cancer (8). Histological examination revealed that it was moderately differentiated adenocarcinoma in adenoma, and that the depth of cancer invasion was confined to the submucosal layer. However, marked cancer infiltration was found in the lymphatic and venous vessels in both the submucosal layer and serosa (Fig. 2). Moreover, regional lymph node involvement was present. Cancer metastasis in the bone marrow was remarkable, especially in the spine. Microscopic lung sections revealed tumor emboli in the blood vessels (Fig. 3). There were no metastases in the liver, adrenal glands or other organs. Although there were erosions in the stomach, there was no evidence of tumor involvement.

\section{Discussion}

Jarcho (9) first reported diffusely infiltrative carcinoma in 1936. Hayashi et al (1) reviewed 40 cases of disseminated carcinomatosis of the bone marrow in Japan. The three major symptoms are anemia, lumbago or/and back pain, and a bleeding tendency. Hematological findings are severe anemia, leukoerythroblastosis and DIC and/or MHA.
Biochemical findings are mild to moderate hyperbilirubinemia, elevation of serum GOT and GPT, and marked elevation of ALP and LDH. Most of the primary cancers are in the stomach (over 90\%). Mucin-forming, diffusely infiltrative, or poorly differentiated carcinomas are most frequently seen histologically $(1,2)$. Metastases to the bone marrow are diffusely infiltrative rather than of a nodular pattern. The present case is in accordance with these clinical features of disseminated carcinomatosis of the bone marrow.

Disseminated carcinomatosis of the bone marrow is often accompanied by DIC or MHA $(1,2)$, and its clinical course is rapid. Brain et al (10) reported that mucin-forming carcinoma is related to DIC or MHA. It has been proposed that the pathogenesis of DIC and/or MHA in cancer is due to tissue thromboplastin-like substances derived from tumor cells and disseminated hematogenous metastases, thus causing damage to vascular endothelial cells $(1,2)$. The pathology is also accelerated by other factors such as infection, anemia and acidosis.

Reports on carcinomatosis of the bone marrow from the colon are rare in Japan (3-7); histological examination revealed that all of these were advanced cancers and mucinforming or poorly differentiated adenocarcinomas in the presented case, moderately differentiated adenocarcinoma in adenoma was seen. Although the depth of invasion was confined to the submucosal layer, lymphatic and venous permeation and diffusely infiltrative bone marrow metastases were found. It is known that the percentage of lymphatic vessel invasion is 5 to $10 \%$ and distant metastasis is very rare even in submucosal invasive carcinoma of the colon $(11,12)$. To our knowledge, this is the first report showing disseminated carcinomatosis of the bone marrow from submucosal carcinoma in adenoma of the rectum.

\section{References}

1) Hayashi H, Haruyama H, Emura Y, Kaizuka I, Ozeki $T$. Disseminated carcinomatosis of the bone marrow - Study of a type of metastatic cancer and relationship of microangiopathic hemolytic anemia or disseminated intravascular coagulation. Jpn J Cancer Clin 25: 329, 1979 (in Japanese).

2) Tsuji Y, Hayakawa A, Yamamoto $\mathrm{K}$, et al. A case of diffusely bone metastasis 11 years after the total resection of early cancer: a review of 43 cases of diffusely infiltrative bone metastasis in Japan, 1977-1980. Saishin Igaku 37: 2243, 1982 (in Japanese).

3) Haratake J, Horie A. Clincopathological study of carcinomatosis of bone marrow. Jpn J Cancer Clin 31: 168, 1985 (in Japanese).

4) Ieki $K$, Ohkubo $Y$, Uehara $K$, Iizuka $M$, Mishima $Y$. A case of diffusely infiltrative colon cancer with DIC. Jpn J Gastroenterol 82: 169, 1985 (in Japanese).

5) Akiyama N, Mikamo S, Sekiguchi M, Fugii G, Yashiro T, Wakabayashi $T$. A case of appendical cancer with disseminated carcinomatosis of bone marrow. Jpn J Clin Surg 48: 123, 1987 (in Japanese).

6) Shikiya T, Tamaki M, Hiyoshi S, Furuki S. A case of recurrent rectal cancer with disseminated carcinomatosis of bone marrow. Okinawa Med J 25: 54, 1988 (in Japanese).

7) Onodera H, Kawamura S, Miyake T, Maekawa I, Osano J, Kanda 


\section{Carcinomatosis and Rectal Cancer}

M. A case of colon cancer with disseminated carcinomatosis of bone marrow in young adult. Gendai Irhyo 22: 451, 1990 (in Japanese).

8) General Rules for Clinical and Pathological Studies on Cancer of Colon, Rectum and Anus (the 4th edition), Japanese Research Society for Cancer of Colon and Rectum, Eds. Kimbara Press, Tokyo, 1985 (in Japanese).

9) Jarcho S. Diffusely infiltrative carcinoma. A hitherto undescribed correlation of several varieties of tumor metastasis. Arch Pathol 22: $674,1936$.
10) Brain MC, Azzopardi JG, Barker LRI, et al. Microangiopathic hemolytic anemia and mucin-forming adenocarcinoma. $\mathrm{Br} \mathrm{J}$ Haematol 18: 183, 1970.

11) Wilcox GM, Anderson PB, Colacchio TA, et al. Early invasive carcinoma in colonic polyp. Cancer 57: 160, 1986.

12) Kodaira S, Teramoto $T$, Hisa $K$, Furukawa $K$, Yamaguchi $H$. Treatment of submucosal invasive carcinoma of the colon and rectum. Stomach and Intestine 26: 849, 1991 (in Japanese). 